\title{
Monitoring and analysis of reinforced concrete plate-column structures under room temperature and fire based on acoustic emission
}

\author{
Dongye Wang \\ Huaqiao University, Xiamen 361021, China \\ Xiamen City University, Xiamen 361008, China \\ WangDY2269@outlook.com
}

Yuli Dong*, Dashan Zhang, Weihua Wang, Xin Lu

Huaqiao University, Xiamen 361021, China

dongy@hqu.edu.cn, zhangds@hqu.edu.cn,whwang@hqu.edu.cn,469316910@qq.com

ABSTRACT. This paper attempts to disclose the damage mechanism of reinforced concrete plate-column structures under room temperature and fire. Several tests were carried out to record the law of crack development on the plate surface under room temperature. The infrared detection technology was adopted to observe how cracks develop under fire. The acoustic emission (AE) signals at different positions of the specimen were monitored by the AE techniques. Coupled with the macroscopic test phenomena, several characteristic parameters collected by the AE system, namely, cumulative number of events, event rate, energy rate and b-value, were analyzed in details. The results show that: the cumulative number of events was active in the loading, heating and cooling stages; the crack density and the change of internal forces could be derived from the trend of event rate; the local energy changes of the specimen could be deciphered from the curves of energy rate and b-value, making it possible to judge if a component has reached the failure state; the specimen suffered the most severe damage, when the AE parameters suddenly changed; AE monitoring enables the early warning of fire to reinforced concrete plate-column structure; infrared detection technology is suitable for real-time monitoring of crack development under high temperature.

KEYWORDS. Plate-column structure; Acoustic emission (AE); Fire test; Cumulative number of events; Event rate; Energy rate; Gutenberg-Richter parameter (b-value).

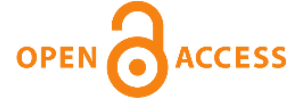

Citation: Wang, D.Y., Dong, Y.L., Zhang, D.S., Wang, W.H., Lu, X., Monitoring and analysis of reinforced concrete plate-column structure under room temperature and fire based on acoustic emission, Frattura ed Integrità Strutturale, 53 (2020) 236-251.

Received: 25.02 .2020

Accepted: 10.05 .2020

Published: 01.07.2020

Copyright: (C) 2020 This is an open access article under the terms of the CC-BY 4.0, which permits unrestricted use, distribution, and reproduction in any medium, provided the original author and source are credited. 


\section{INTRODUCTION}

A

coustic emission (AE) refers to the phenomenon that the local defects of materials or components release strain energy in the form of elastic wave, under external conditions like stress, temperature and magnetic field [1]. The $\mathrm{AE}$ sources could be generated by a variety of mechanisms, including impact, combustion, pressure leakage, phase change, plastic deformation, as well as crack formation and propagation in solid materials. Each source generation mechanism produces a unique type of AE signals. Whichever the mechanism, the AE is always a process in which a material is locally or partly destabilized under changing external conditions, and releases energy to reach a new equilibrium.

$\mathrm{AE}$ signals and techniques have often been used to monitor dynamic processes, namely, how materials deform on the microscale under load, and how cracks emerge and develop. Studies have shown that the AE signals (parameters) correspond to the material features and the mechanical changes in structures. Based on the correspondence, the working state of structures can be monitored dynamically and evaluated easily at a fast speed. The application scope of AE techniques has widened from the detection of pressure vessels, metal fatigue and metal fractures to various industrial fields, such as initial detection of pressure vessels and metal fatigue and fracture to many industrial fields such as aerospace, railway, construction, shipbuilding, and electricity [2, 3].

In civil engineering, AE techniques have been successfully adopted to test mainstream materials like concrete and steel, triggering widespread interest in academia. On AE testing of concrete, most scholars focus on monitoring the static and dynamic damage of concrete structures. Chen et al. [4] and Kim et al. [5] investigated the features of AE signals from concrete under compression, and analyzed the correspondence between the degree of concrete damage and the features of AE signals. Zhang et al. [6] elaborated that AE signals like cumulative signal strength and historical index can reflect the corrosion state of steel bars well, but cannot accurately quantify the degree of corrosion damage. Patil et al. [7] applied AE and electrochemical techniques to examine the evolution of steel bar corrosion, and its impact on concrete cracking. Calabrese et al. [8] conducted long-term corrosion monitoring of steel bars in concrete through cluster analysis and denoising. Some scholars [9-12] employed the AE to monitor the mechanical performance of basic components, and probed deep into the AE features of reinforced concrete beams, plates and columns during the damage process. Their studies mainly focus on band energy features, Gutenberg-Richter parameter (b-value), macro/micro evolution, and Kaiser effect. Men et al. [13] introduced the moment-tensor inversion in seismic engineering to quantify the damage of reinforced concrete components, and deduced the expressions for the moment-tensor inversion of cracking mechanism, providing a novel analytical tool based on AE signals.

On AE testing of steel, some scholars [14-20] have conducted in-depth research on the AE features of traditional problems (e.g. steel damage at different tensile rates, and fatigue crack propagation of steel structures), and analyzed the relevant characteristic parameters. For example, Prabhu et al. [21] monitored the creep fracture limit of stainless steel pipes in realtime online. Taking Q345R steel as an example, Li et al. [22] designed a special fixture guided wave mechanism for creep AE, which breaks through the temperature limit of sensors, and carried out corresponding AE monitoring experiments.

In recent years, scholars have made some interesting discussions on the acoustic emission test of concrete, rock, cement and other aspects [23-26]. Currently, the AE techniques are mostly applied to reinforced concrete structures at room temperature. Few have implemented $\mathrm{AE}$ techniques to predict the working performance and failure mode of building structures under fire and high temperature. Guo et al. [27] tested the mechanical performance of post-fire concretes of different strength grades, and discussed the influence of high temperature on the AE in concrete damage process, laying the basis for safety evaluation of tunnel lining concrete structures under fire and high temperature. Zhu [28, 29], Yang [30] measured the $\mathrm{AE}$ features of two-way reinforced concrete plates in the overall structure, examined the changes in the number of AE events, energy rate and b-value of the plates under fire, and identified the correlation of each parameter with crack development, furnace temperature and vertical displacement of the plates. Through their research, the AE techniques are successfully adopted to monitor the mechanical properties of two-way reinforced concrete plates under fire and high temperature, expanding the application scope of AE techniques.

Reinforced concrete plate-column structure is a common structural system. In the event of a fire, the structure may suffer from punch failure, even if it is not overloaded. In 2004, a car caught fire in an underground garage with slab-column structure, Gretzenbach, northwestern Switzerland. The nodes of the plate-column were penetrated and then collapsed continuously, killing 7 firefighters [31]. Thus, firefighters and rescuers are very concerned about the safety of reinforced concrete plate-column structure under fire. This paper carries out tests on reinforced concrete plate-column structure under room temperature and fire, and places $\mathrm{AE}$ sensors on plate surfaces to collect AE signals from different parts. Next, the $\mathrm{AE}$ features of reinforced concrete plate-column structure under fire were explored, in the light of the characteristic parameters (e.g. cumulative number of events, event rate, energy rate and b-value) and the macroscopic test phenomena. The research results lay the foundation for an AE-based early warning system for collapse room temperature and fire. 


\section{METHODOLOGY}

\section{Specimen design}

hree specimens, denoted as S1-3, with the same size were designed according to the provisions of the relevant code [32]. The plate is $4.8 \mathrm{~m}$ in length $\left(l_{1}\right), 4 \mathrm{~m}$ in width $\left(l_{2}\right)$ and $0.2 \mathrm{~m}$ in thickness $(b)$. The square column is $0.4 \mathrm{~m}$ in side length (a) and $1.6 \mathrm{~m}$ in height. Beneath the column, there is a foundation with the side length of $1.4 \mathrm{~m}$ and thickness of $0.3 \mathrm{~m}$. The vertical view and photo of a specimen are given in Fig. 1(a) and Fig. 1(b), respectively.

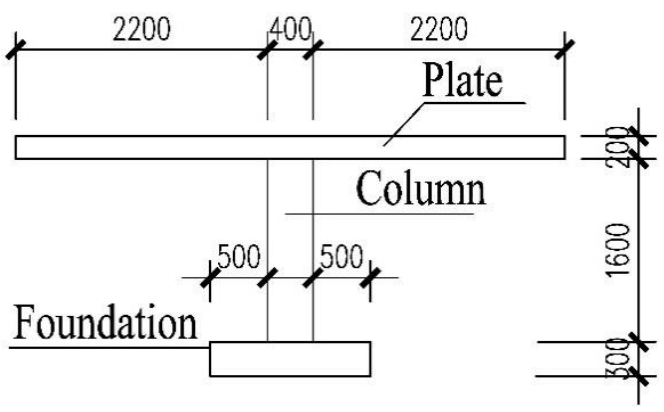

(a): Vertical view of the specimen.

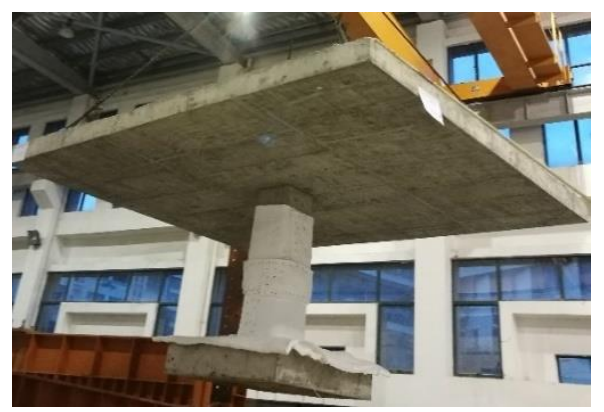

(b): Photo of the specimen.

Figure 1: Vertical view and photo of the specimen.

The specimens were made with commercial concrete and cured for 221 days. For each specimen, three $150 \times 150 \times 150 \mathrm{~mm}$ standard concrete cubes were taken and cured under the same conditions as the specimens. On the test day, the mean compressive strength $f_{\text {cu }}$ of the concrete cubes was measured as $54.3 \mathrm{MPa}$, i.e., by using a microcomputer-controlled electrohydraulic servo universal testing machine [33].

HRB400 steel bars were selected and subjected to pull-out tests [34]. The standard values of the yield strength $f_{\mathrm{yk}}$ and the ultimate strength $f_{\text {stk }}$ of the steel bars were measured through the tests. Then, the mean design strength $f_{\mathrm{y}}$ of the steel bars was derived as $412 \mathrm{MPa}$ [32]. The plate was reinforced by two layers of bidirectional steel bars, with a diameter of $12 \mathrm{~mm}$, a spacing of $150 \mathrm{~mm}$ and a $20 \mathrm{~mm}$-thick protective layer. The column was reinforced by eight $20 \mathrm{~mm}$-diameter longitudinal steel bars, and $8 \mathrm{~mm}$-diameter stirrups, with a spacing of $100 \mathrm{~mm}$. The foundation was reinforced at the bottom by bidirectional steel bars, with a diameter of $16 \mathrm{~mm}$ and a spacing of $200 \mathrm{~mm}$. The reinforcement of each specimen is illustrated in Figs. 2.

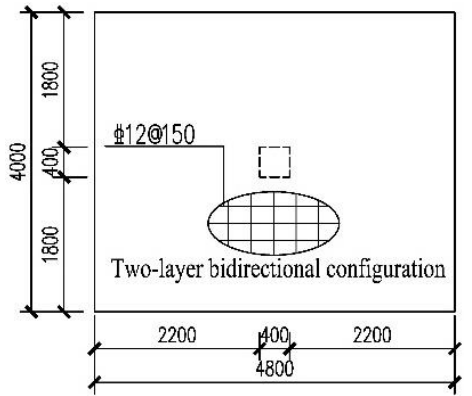

(a): Planar reinforcement of the specimen.

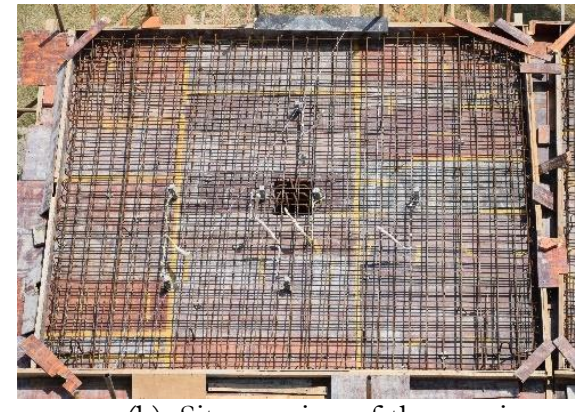

(b): Site pouring of the specimen

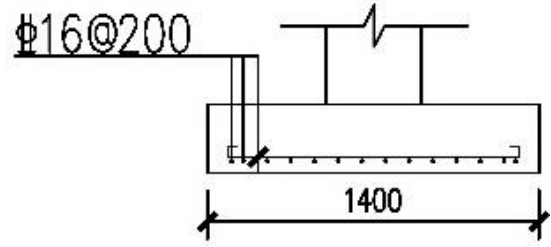

(c): Reinforcements of the column and the foundation.

Figure 2: Reinforcement information and photos of specimen 
Fire test furnace

The tests were performed in a combined horizontal fire furnace in the structural laboratory of Huaqiao University. The net size of the furnace is $5.95 \mathrm{~m}$ in length, $4.31 \mathrm{~m}$ in width and $1.5 \mathrm{~m}$ in height. Three burners were installed on the long side of the furnace, and two on the short side. To correctly install and position specimens, a movable partition wall was added in the fire furnace. Two burners were arranged in the middle of the wall, with a spacing of $2.8 \mathrm{~m}$. Fig. 3(a) shows the jet flame of the burners. On the unexposed surface of the wall, a $0.3 \mathrm{~m}$-wide steel platform was set up for applying the fireproof cotton (Fig. 3(b)). After the wall is fixed, the net distance from the edge of the exposed surface to the inner edge of the short side of the furnace is $3.7 \mathrm{~m}$.

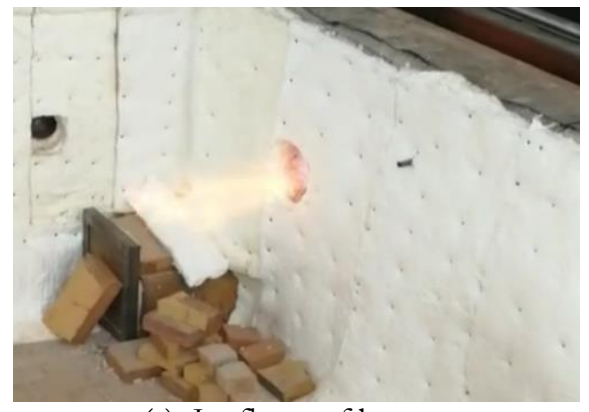

(a): Jet flame of burners.

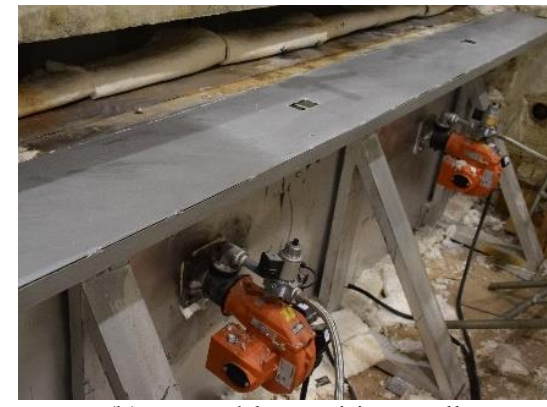

(b): Movable partition wall.

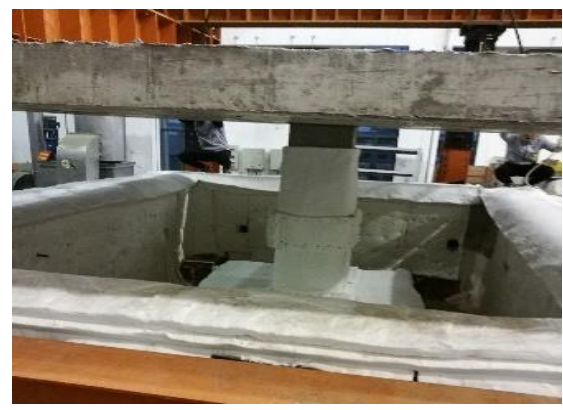

(c): Lifting and installation of specimen

Figure 3: Fire furnace reconstruction and lifting and installation of specimen

\section{Loading plan and fire plan}

Before the test, the column and its foundation were covered by aluminum silicate fireproof cotton. As shown in Fig. 3(c), each specimen was lifted into the horizontal fire furnace by the lifting equipment in the lab. Once the specimen was in place, the plate surface is about $0.3 \mathrm{~m}$ taller than the movable partition wall.

According to the provisions of reference [32], the punching bearing capacity of slab without stirrup under local load or concentrated reaction is

$$
F_{1} \leqslant 0.7 \beta_{\mathrm{h}} f_{\mathrm{t}} \eta u_{\mathrm{m}} h_{0}
$$

$\beta_{\mathrm{h}}$ : the influence coefficient of section height $\mathrm{h}$, when $h \leqslant 800 \mathrm{~mm}, \beta_{\mathrm{h}}=1.0$, when $\mathrm{h} \geqslant 2000 \mathrm{~mm}, \beta_{\mathrm{h}}=0.9$, and the middle is taken as linear interpolation method; $f_{t}$ design value of concrete tensile strength; $\eta$ shall be calculated according to the following two Equations, and the minimum value shall be taken:

$$
\begin{aligned}
& \eta_{1}=0.4+\frac{1.2}{\beta_{s}} \\
& \eta_{2}=0.5+\frac{\alpha_{s} b_{0}}{4 u_{m}}
\end{aligned}
$$

$\beta_{\mathrm{s}}$ : the ratio of the long side to the short side of the rectangular time in the local load or concentrated reaction area, and $\beta_{\mathrm{s}}$ should not be greater than 4 . When $\beta_{\mathrm{s}}$ is less than 2 , it is taken as 2 ; for the circular cutting surface, it is taken as $2 . \alpha_{\mathrm{s}}$ is the influence coefficient of column position: middle column $\alpha_{\mathrm{s}}=40$; side column $\alpha_{\mathrm{s}}=30$; corner column $\alpha_{\mathrm{s}}=20 . u_{\mathrm{m}}$ : critical section perimeter, take the perimeter of the plate section at $0.5 h_{0}$ away from the column edge; $h_{0}$ : effective height of the plate.

For the members in this paper, $f_{\text {cu }}$ can be used to calculate the average $f_{\mathrm{t}}=1.95 \mathrm{~N} / \mathrm{mm} 2, h_{0}=165 \mathrm{~mm}$. After calculation, $F_{1}=509 \mathrm{kN}$ at room temperature.

In the design of loading target value, the ratio of punching force and $F_{1}$ on the column is about $60-70 \%$. The dead weight of the test piece plate is about $100 \mathrm{kN}$, and the dead weight of the first level distribution beam (only one) and the second level distribution beams (there were two beams) in the loading device is about $25 \mathrm{kN}$. During the test, the target loading value is rounded and the final target loading value is determined to be $200 \mathrm{kN}$. 
To reach the target load of $200 \mathrm{kN}$, the load was applied by a jack with a measuring range of 1,000 kN, and transmitted to four loading points through two stages of distribution beams. There is one primary distribution beam and two secondary distribution beams. The total dead weight of these beams stood at $25 \mathrm{kN}$.

The primary distribution beam, connected to the jack via a ball hinge, was placed right between the two secondary distribution beams. A steel roller (diameter: $45 \mathrm{~mm}$ ) was added between the two stages of beams and cushioned with a 200 $\mathrm{mm} \times 350 \mathrm{~mm}$ baseplate. Each secondary distribution beam was deployed close to the edge of the short side of plate surface. A steel roller (diameter: $45 \mathrm{~mm}$ ) was added between the beam and the edge and cushioned with a $300 \mathrm{~mm} \times 300 \mathrm{~mm}$ baseplate. Before the beam was in place, the outer edge of the baseplate was fixed at $0.4 \mathrm{~m}$ from the edge of the short side of plate surface. To prevent rollers from falling off under load, two $15 \mathrm{~mm}$-diameter steel rods were welded to each baseplate. Fig. 4(a) provides the details on the steel rollers and baseplates. Fig. 4(b) shows both the specimen and the testing arrangement.

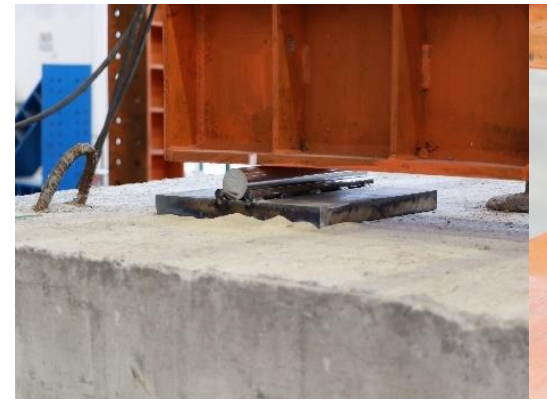

(a) Details of the roller.

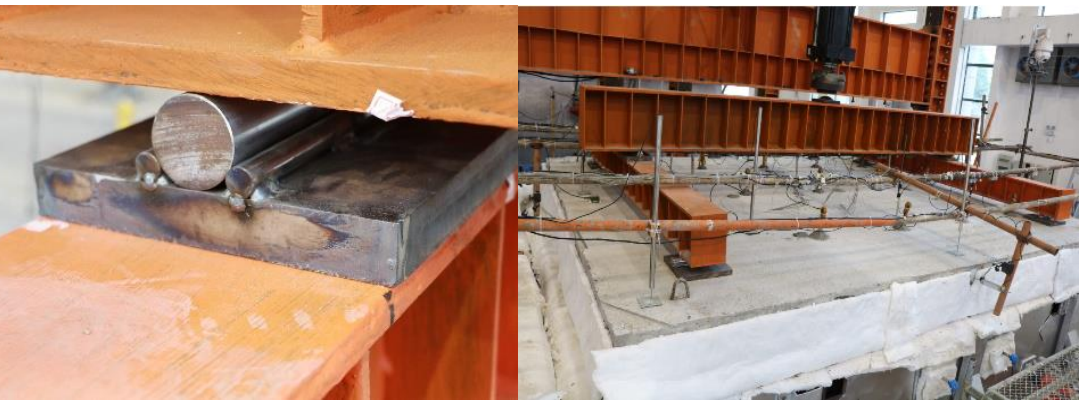

(b) Relative position between test device and specimen.

Figure 4: Details of the roller and relative position between test device and specimen.

Before the fire test, each specimen was loaded preliminarily in five stages at room temperature. The target loads of the five stages were 50,100, 150, 175 and $200 \mathrm{kN}$, respectively. From the first to fourth stages, each target load was held for $10 \mathrm{~min}$. On the fifth stage, the aluminum silicate fireproof cotton was applied after reaching the target load. Specifically, the fireproof cotton was folded into L-shape: one side on the side of the reinforced concrete plate of the specimen, and the other side on the furnace wall or the upper edge of the partition wall, extending to the fixed steel beam outside the furnace wall or to the steel platform outside the wall. The fireproof cotton was kept in place by fire bricks (Fig. 5). The pre-loading lasted 47 min for S1, 32 min for S2 and 65 min for S3. The duration of each fire test was $3 \mathrm{~h}$.

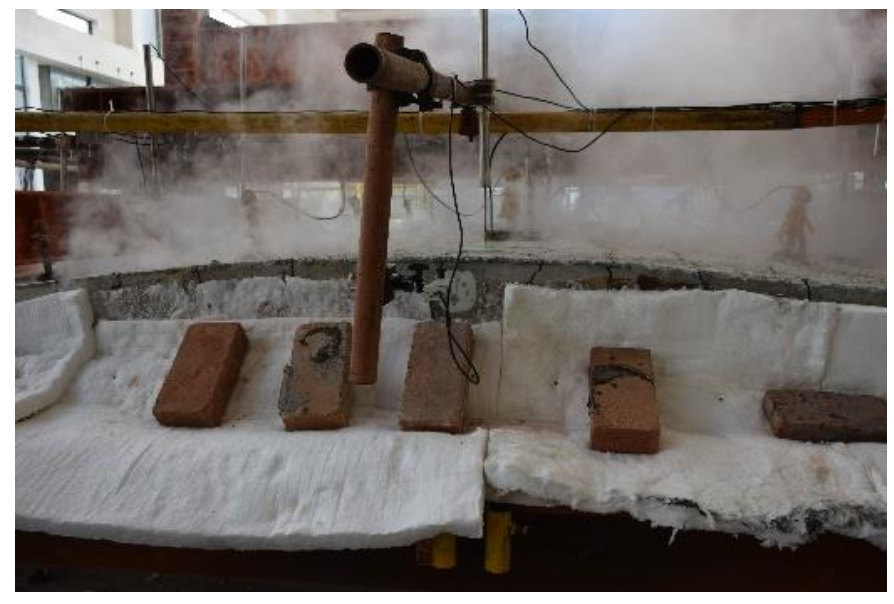

Figure 5: Application of fireproof cotton.

\section{Infrared observation}

In the event of a fire, the crack development on plate surfaces can be recorded in real-time by infrared detection technology [35]. In our tests, the temperature field and crack development on the plate surface were observed by a fully digital dynamic infrared thermal monitoring device (Fig. 6). 


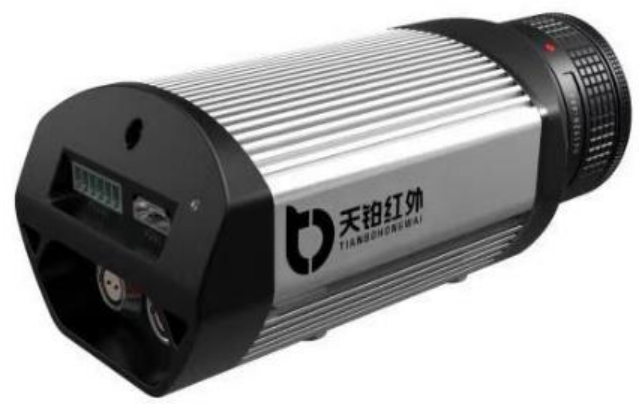

Figure 6: Infrared monitoring device.

\section{DEPLOYMENT OF AE SYSTEM AND SENSORS}

7 his paper adopts the Micro-II multi-channel digital AE system with a PCI-E acquisition card. As shown in Fig. 7a, fifteen $\mathrm{AE}$ sensors were deployed on the plate surface to record the AE signals at different positions, considering how plate cracking affects the generation and propagation of AE signals under fire. The working principle of $\mathrm{AE}$ is illustrated in Fig. 7b. Tab. 1 describes the setting of AE system and sensors.

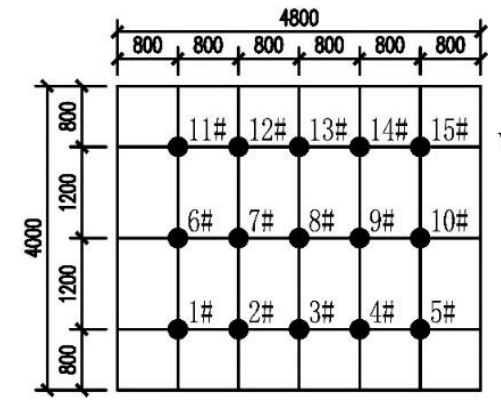

(a) AE mesuring points

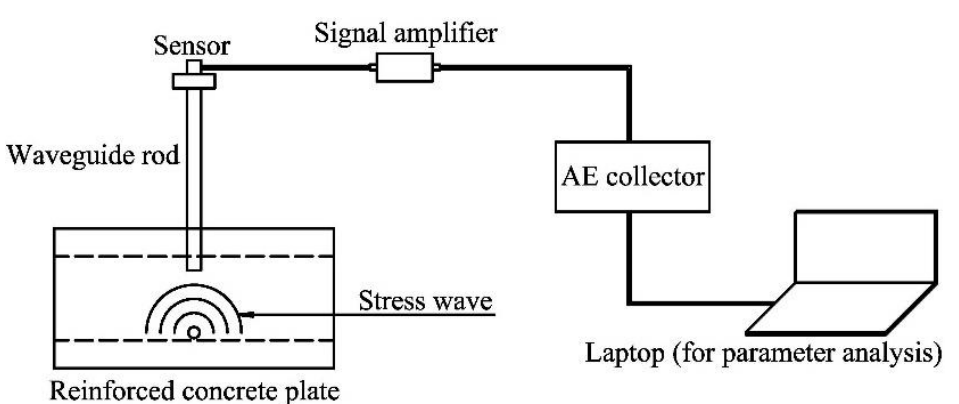

(b) Working principle of $\mathrm{AE}$

Figure 7: Layout of AE measuring points and working principle of AE.

\begin{tabular}{ccccccc}
\hline Sensor & $\begin{array}{c}\text { Sampling } \\
\text { frequency }(\mathrm{kHz})\end{array}$ & $\begin{array}{c}\text { Threshold } \\
(\mathrm{dB})\end{array}$ & $\begin{array}{c}\text { Preamplifier } \\
(\mathrm{dB})\end{array}$ & \multicolumn{2}{c}{ Waveform setting } & $\begin{array}{c}\text { Number of } \\
\text { sensors (each) }\end{array}$ \\
$\begin{array}{c}\text { R6-A } \\
\text { resonance type }\end{array}$ & $20 \sim 100$ & 40 & 40 & $\begin{array}{c}\text { Sampling rate } \\
\text { (MSPS) }\end{array}$ & $\begin{array}{c}\text { Length (number } \\
\text { of points) }\end{array}$ & 15 \\
\hline
\end{tabular}

Table 1: Setting of AE system and sensors.

\section{Plate damage phenomena}

\section{Macro phenomena}

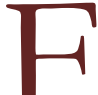

rom 0 to $1 \mathrm{~min}$ at room temperature, as the load applied by the jack gradually reached $50 \mathrm{kN}$, there was no obvious cracking or deformation on the plate surface.

From 14 to $15 \mathrm{~min}$, the load increased from 50 to $100 \mathrm{kN}$. During this process, five fine cracks appeared almost simultaneously on the plate surface on the east and west long sides, respectively. The cracks were symmetrically distributed about the central axis of the long sides, with a spacing of 15-18 cm. The cracking positions basically overlap those of steel bars on the plate surface. Besides, cracks $1 \#$ on both east and west sides propagated to the center of the column. The crack width on the edge of the plate fell between 0.20 and $0.40 \mathrm{~mm}$.

From 26 to $28 \mathrm{~min}$, the load further grew from 100 to $150 \mathrm{kN}$. During this process, two new cracks emerged on the east long side, and one on the west long side. At $30 \mathrm{~min}$, two more cracks were observed on the east long side, and five on the west long side. The crack development was accompanied by a crisp sound similar to that of grains falling on the ground. 
The new cracks were $16-18 \mathrm{~cm}$ away from the original cracks. The cracks $1 \#$ and $3 \#$ on the east side and the cracks $2 \#$ and $3 \#$ on the west side propagated to the center of the column, while the original cracks became wider. On the edge of the plate, multiple cracks grew deeper into the plate. The crack width on the edge of the plate fell between $0.12 \mathrm{and} 1.40 \mathrm{~mm}$. From 38 to $39 \mathrm{~min}$, the load climbed up from 150 to $175 \mathrm{kN}$. During this process, four new cracks emerged on the east long side, and four on the west long side. The new cracks were 16-22 cm away from the original cracks. The original cracks quickly widened and grew deeper into the plate, giving off a clear cracking sound. On the east and west sides, several cracks penetrated the edges of plate-column nodes. The areas of plate-column nodes were cracked and developed into a closed diamond shape with wide cracks. The crack width on the edge of the plate fell between 0.18 and $2.2 \mathrm{~mm}$.

From 49 to $50 \mathrm{~min}$, the load continued to rose from 175 to $200 \mathrm{kN}$. During this process, two new cracks emerged on the east long side, and one on the west long side. In the areas of plate-column nodes, cracks developed quickly and became rather wide $(10 \mathrm{~mm})$. The original cracks widened quickly. The crack width on the edge of the plate fell between 0.38 and $2.8 \mathrm{~mm}$. Fig. 8 presents the crack development at room temperature.

The furnace was ignited at $105 \mathrm{~min}$. From 114 to $118 \mathrm{~min}$, the furnace temperature was between 654 and $727{ }^{\circ} \mathrm{C}$. Six popping sounds were heard consecutively, due to concrete spalling. At $119 \mathrm{~min}$, the furnace temperature increased to 736 ${ }^{\circ} \mathrm{C}$. Water stains started to appear simultaneously in the cracks on the north and south sides of the plate, and seeped to the short sides. Meanwhile, two concrete spalling sounds were heard. At $121 \mathrm{~min}$, the furnace temperature was $763{ }^{\circ} \mathrm{C}$. Four sounds of concrete spalling were heard; lots of water stains appeared in the cracks on plate surface, and seeped towards the short sides; water vapor escaped from the relatively width cracks (Fig. 9). One concrete spalling sound was heard respectively at 131 and $133 \mathrm{~min}$. At $140 \mathrm{~min}$, the furnace temperature rose to $857^{\circ} \mathrm{C}$. The plate height was distorted at the top of the column. At $252 \mathrm{~min}$, the furnace temperature was $1,078{ }^{\circ} \mathrm{C}$, and the water stains on the plate surface were basically evaporated. At $315 \mathrm{~min}$, the fire was turned off.

Fig. 10 displays the distribution of cracks in the thickness direction on the long sides of the plate. It can be seen that, in the thickness direction, longitudinal cracks developed and extended to $3 / 4$ of plate thickness, without penetrating the plate. The spacing of the cracks was basically the same as the steel bars on the plate. After flameout, the cracks on the top of the plate radiated from the center to the edges (Fig. 11).

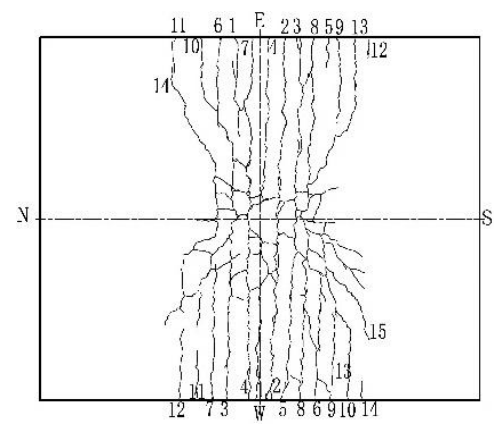

(a) $\mathrm{S} 1$

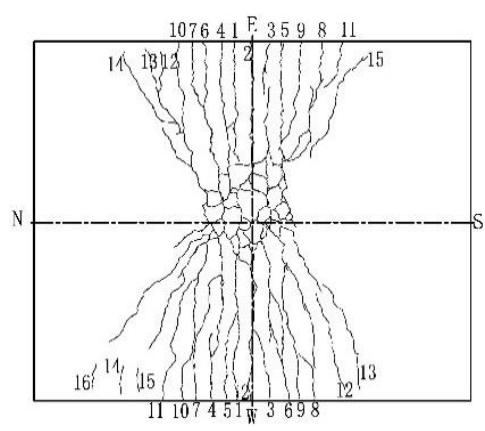

(b) S2

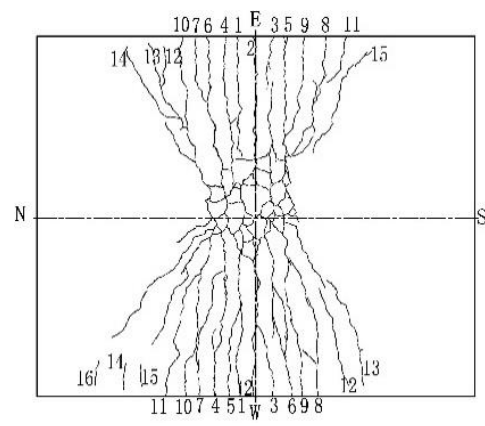

(c) $\mathrm{S} 3$

Figure 8: The crack development at room temperature.

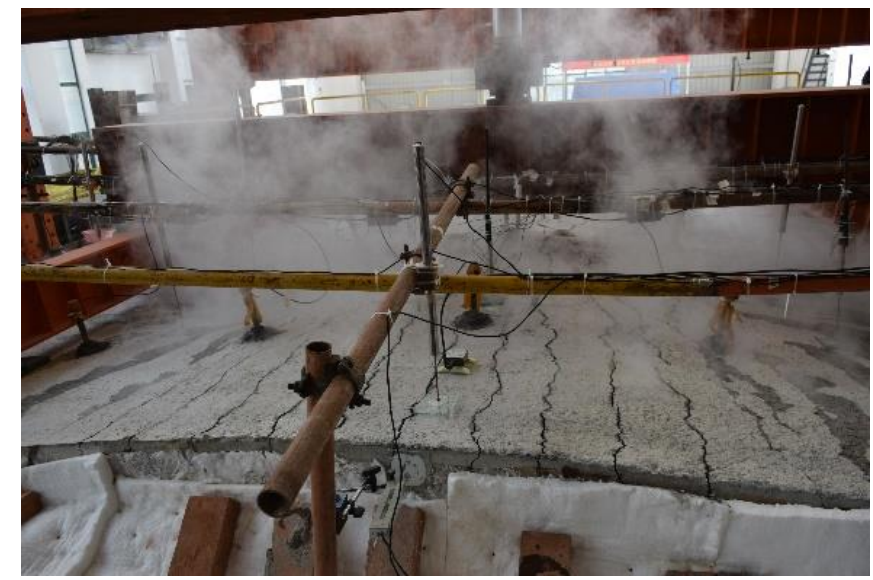

Figure 9: Water stains and water vapor on the plate surface. 


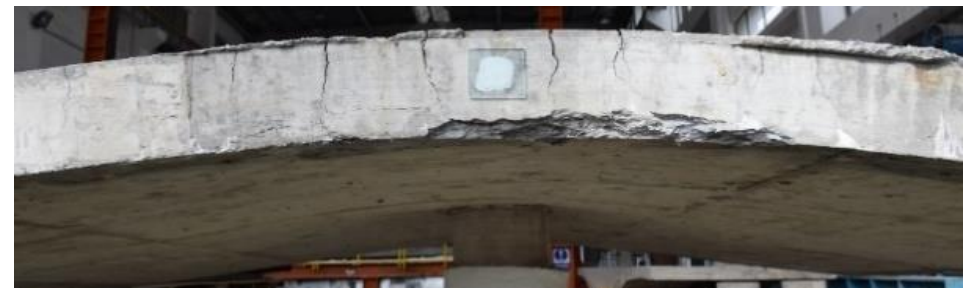

Figure 10: Crack distribution in the thickness direction on the long sides of the plate.

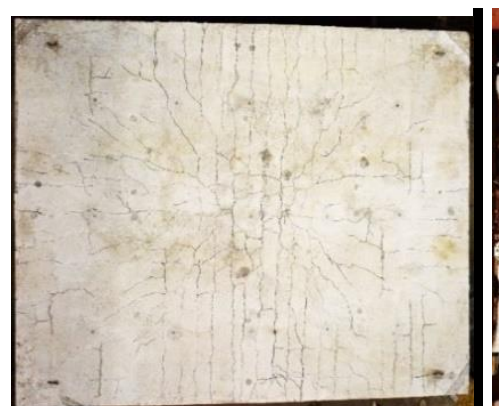

(a) S1

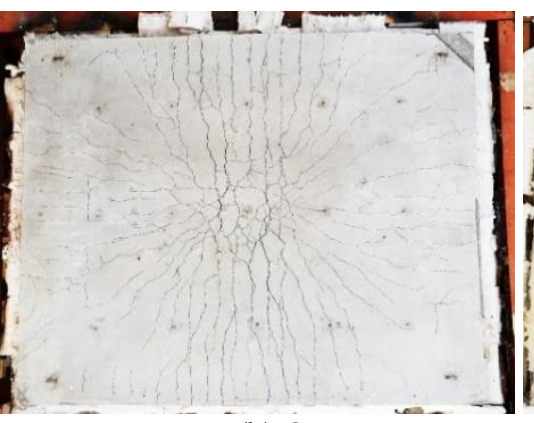

(b) S2

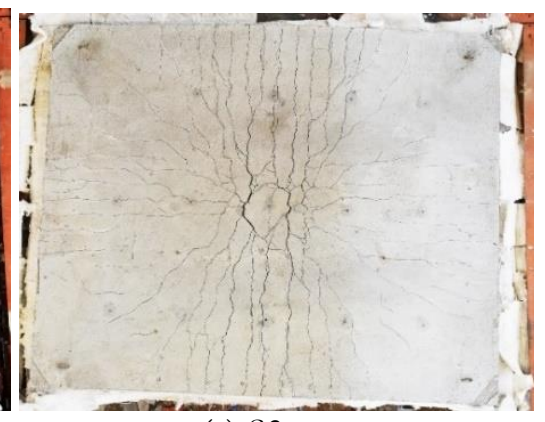

(c) $\mathrm{S} 3$

Figure 11: Crack distribution on the top of the plate.

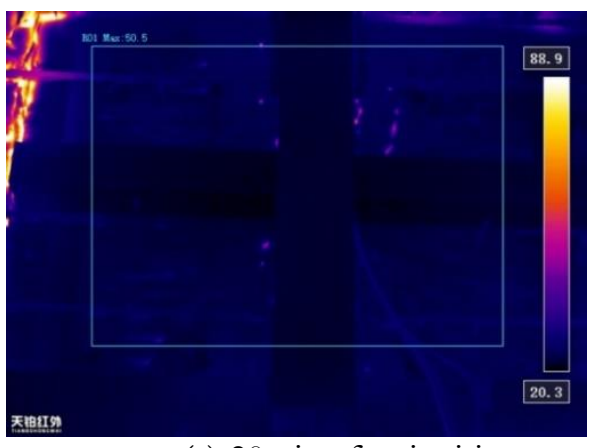

(a) $20 \mathrm{~min}$ after ignition

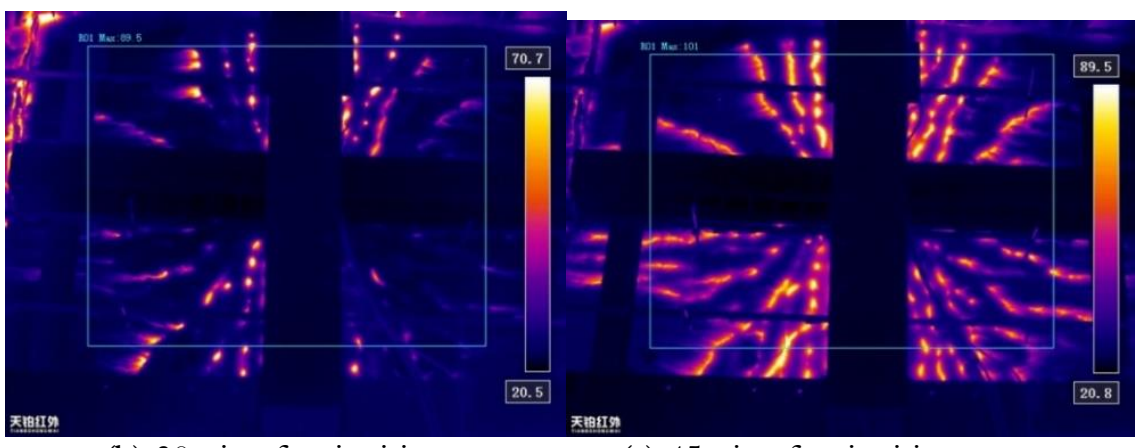

(b) 30min after ignition (c) $45 \mathrm{~min}$ after ignition

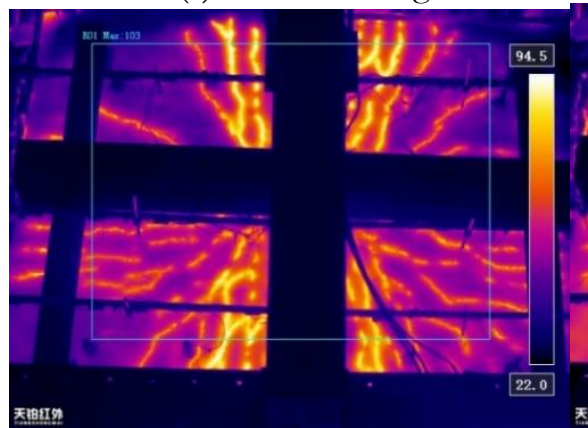

(d) $75 \mathrm{~min}$ after ignition

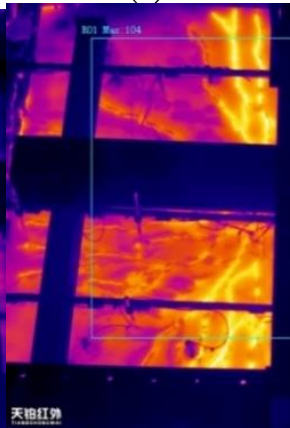

(e) 120min after ignition
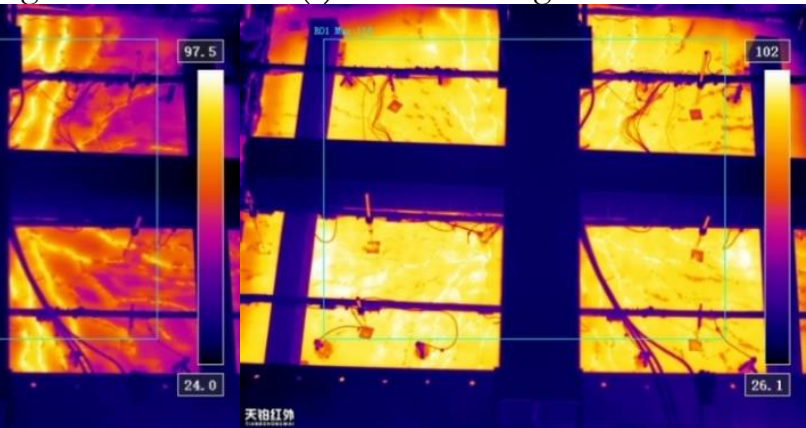

(f) 210min after ignition (flameout)

Figure 12: Crack development on the top of the plate of $S 3$ under fire.

Crack development on plate surface under fire

In the fire test, the plate surface was covered by lots of water stains and water vapor, making it difficult to observe crack distribution and development with the naked eye. To overcome the difficulty, infrared detection technology was introduced to monitor the plate crack development. For the lack of space, this paper only provides the crack development of S3 in six stages after ignition, which was captured by our infrared thermal monitoring device (Fig. 12). The crack development in plate-column was not captured, for the device was installed directly above the specimen (i.e. the central nodes were blocked by the loading beams and distribution beams). 
As shown in Fig. 12, at 125 min (20 min after ignition), several hot spots formed in the longitudinal cracks near the center of the plate surface, indicating that the longitudinal cracks near the center were wider than those in other places.

At $135 \mathrm{~min}$ (30 min after ignition), hot spots were clearly visible on several large longitudinal cracks and individual diagonal cracks. The radiating contour of cracks on the plate was faintly visible, and the cracks on the north and south sides developed in a uniform manner.

At $150 \mathrm{~min}$ (45 min after ignition), there were lots of water stains on the plate surface. Through our infrared thermal monitoring device, the hot spots were clearly visible on each crack, and the cracks were radiating from the center on the plate surface. Moreover, the hot spots were plump and hot in the longitudinal cracks along the long sides. This means the longitudinal cracks are wide, and much heat is transmitted to the plate surface. By contrast, there were few low-temperature hot spots in diagonal cracks and transverse cracks, indicating that these cracks are relatively narrow.

At $180 \mathrm{~min}$ (75 min after ignition), the hot spots in diagonal cracks were as plump as those in longitudinal cracks, and new short diagonal cracks formed at the corner of the plate.

At $225 \mathrm{~min}$ (120 min after ignition), the temperature at other positions of the plate gradually approached the temperature in the cracks.

At 315 min (flameout), the shape of the cracks of the plate surface was illegible.

\section{AE DATA ANALYSIS}

here are two major types of AE parameters: basic parameters and characteristic parameters. Basic parameters refer to the frequency and time domain parameters directly measured by the AE device. Basic parameters can be further divided into three categories: cumulative count parameters, statistical parameters, and rate of change (ROC) parameters. The most common cumulative count parameters include the cumulative number of events, total energy, total ring count, and total amplitude count. Typical examples of statistical parameters are amplitude distribution, frequency distribution, and duration distribution. The ROC parameters demonstrate the change of an AE parameter per unit time. Being quantities of states, popular ROC parameters like event rate and energy rate are closely correlated with the internal change of materials.

The AE parameters reflect the differences between various states or projects. There is no uniform standard for the selection of such parameters. Instead, the AE parameters should be chosen to fully manifest the AE process and state, according to the scope and purpose of each research. The b-value is one of the most commonly chosen AE parameter.

Based on the macroscopic phenomena and AE signals, this paper selects such four parameters as cumulative number of events, event rate, energy rate and b-value to disclose the time-varying AE features. Since the sensors are deployed symmetrically, the data collected by six $(7 \#, 8 \#, 11 \#, 12 \#, 13 \#$ and 15\#) out of the fifteen sensors (Fig. 7a) were selected for further analysis. For the lack of space, specimen S3 was taken as an example in the following discussion.

\section{Cumulative number of events}

The AE event is defined as a local change in the material that emits acoustic waves. The total count of all events in a process is called the cumulative number of events. This parameter reveals the time of crack emergence and the degree of crack development. The maximum cumulative number of events demonstrates the development and density of cracks at the measuring point, providing a yardstick of source activity. Fig. 13 shows the variation in the cumulative number of events at each measuring point of S3 with time and furnace temperature. Obviously, the entire process can be divided into the following three phases.

The first phase is the staged loading at room temperature. In the first $72 \mathrm{~min}$, the cumulative number of events surged up at each measuring point. The fastest growth rate $(124$ events $/ \mathrm{min})$ appeared at $8 \#$ at the center of the plate, with a cumulative number of events of 8,899 . The cumulative number of events was relatively large $(8,000)$ at $12 \#, 13 \#$ and $15 \#$, which were arranged along the long side. The above results show that the central nodes of the plate were relatively active in the staged loading at room temperature, resulting in a high density of cracks. This agrees well with the macroscopic phenomenon that ring cracks continuously emerge in the area of these nodes. In addition, the nodes along the long side were more active than those along the short side, which is in line with the macroscopic phenomenon that longitudinal cracks mainly develop along the long sides.

In the second phase, the fire was ignited and the furnace temperature started to rise. In this case, the cumulative number of events increased sharply and then stabilized. The sharp increase occurred between 106 and 143 min when the furnace temperature jumped from to $868^{\circ} \mathrm{C}$. In this phase, numerous diagonal cracks emerged, and the longitudinal cracks formed under room temperature continued to expand, causing the concrete at the bottom of the plate to spall. Echoing with 
macroscopic phenomena, the cumulative number of events at all measuring points rocketed up, with growth rates of 82.8 , 98.2, 62.5, 65.0, 34.7, and $94.1 \%$, respectively. The growth rates at $8 \#$ and $15 \#$ both surpassed $90 \%$. Hence, in the heating phase, the area of plate-column nodes was still more active and more severely damaged than the other places. The relatively large cumulative number of events at $7 \#$ signifies the generation of many diagonal cracks.

In the third phase, the fire was turned off, and the furnace cooled down. In this case, the cumulative number of events rose rapidly for a while by less than $10 \%$ and then stabilized.

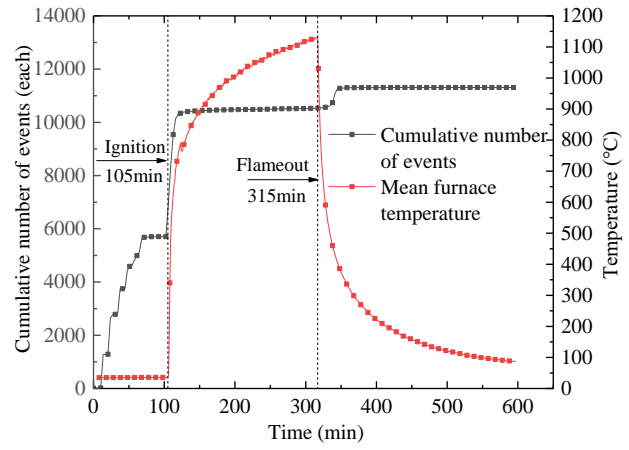

(a) 7-channel sensor

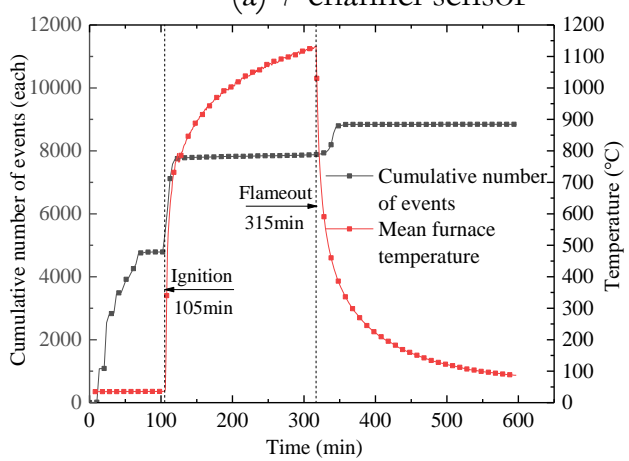

(c) 11-channel sensor

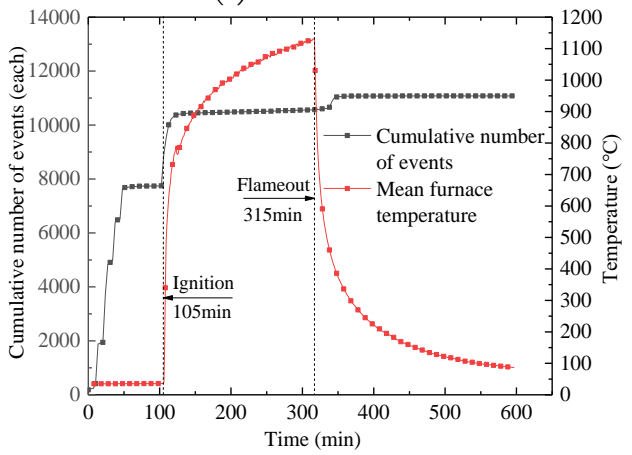

(e) 13-channel sensor

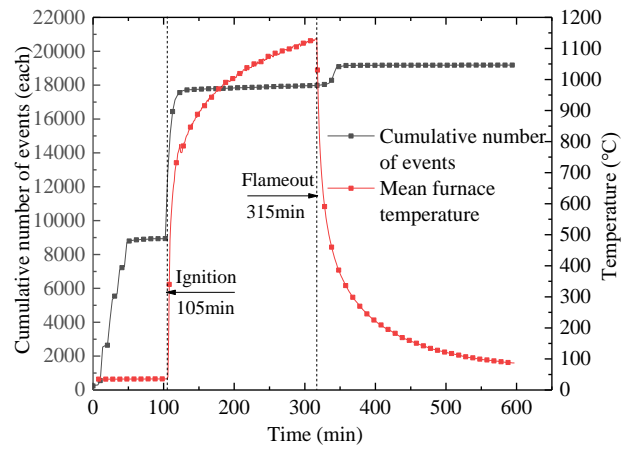

(b) 8-channel sensor

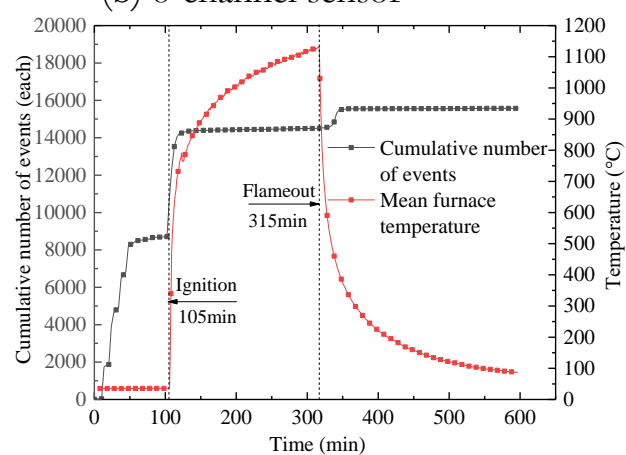

(d) 12-channel sensor

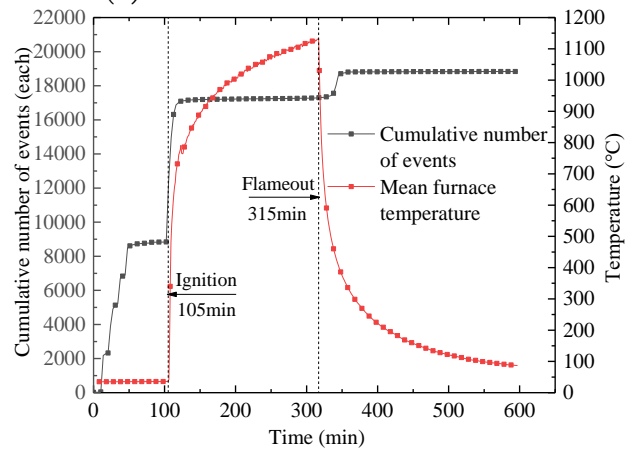

(f) 15-channel sensor

Figure 13: Variation in the cumulative number of events of S3 with time and furnace temperature.

\section{Event rate, energy rate and b-value}

The event rate reflects the change of events measured per unit time, providing an indicator of crack density.

The AE energy (unit: $\mathrm{mv} \cdot \mu \mathrm{s}$ ) is not an energy in the physical sense. This parameter is defined as the area under the envelope of the signal waveform, reflecting the signal intensity. Generally, the square of the amplitude and duration of AE signals can both serve as energy parameters. The internal damage or surface cracking that emit acoustic waves are often accompanied by energy generation. The change of energy measured per unit time, i.e. energy rate, can reflect the degree of cracking and internal damage of the concrete.

The b-value, an important parameter in seismic analysis, was originally used to characterize the relationship between seismic frequency and magnitude. With the proliferation of AE techniques, b-value has been adopted to analyze the AE signals of building structures under fire.

The relationship between the number of events $\mathrm{N}$ and the amplitude $\mathrm{A}$ can be expressed as: 


$$
\log N=a-b \log A
$$

where, $a$ is a constant.

There are many different definitions on the b-value of concrete. Here, the physical meaning of b-value [36] is defined as the degree of cracking on the plate surface under fire. The b-value is negatively correlated with the crack width and the proportion of large-amplitude signals in AE signals [citation suggested]. The b-value can be adopted to evaluate the degree of internal damage of concrete.

Under the effects of various small defects and errors, our specimens exhibited complex mechanical behaviors in the tests. As a result, there might be a certain degree of dispersion in the event rate, energy rate and b-value at each measuring point. It would be one-sided and incomprehensive to analyze only one parameter at a single measuring point. To correlate $\mathrm{AE}$ signals with macroscopic phenomena, this paper decides to jointly analyze all three characteristic factors: event rate, energy rate and b-value.

The analysis shows that the variation in the three characteristic factors can be split into several stages. For convenience, the entire process of room temperature loading and fire test was divided into the following five stages:

(1) Room temperature stage I: the stage before any crack appeared on the specimen. This stage lasts from the start of the test to the completion of the first loading stage at room temperature.

(2) Room temperature stage II: the stage of crack emergence and development. This stage lasts from the start of the second loading stage to the completion of the fifth loading stage at room temperature.

(3) High temperature stage I: the stage of active AE signals. This stage lasts from the start of the fire test to 40min after ignition.

(4) High temperature stage II: the stage of stable AE signals. This stage lasts from the moment the furnace temperature surpassed $900{ }^{\circ} \mathrm{C}$ to the end of the fire test.

(5) Cooling stage: after the end of the fire test, the internal forces of the concrete plate were redistributed, and some sensors received AE signals.

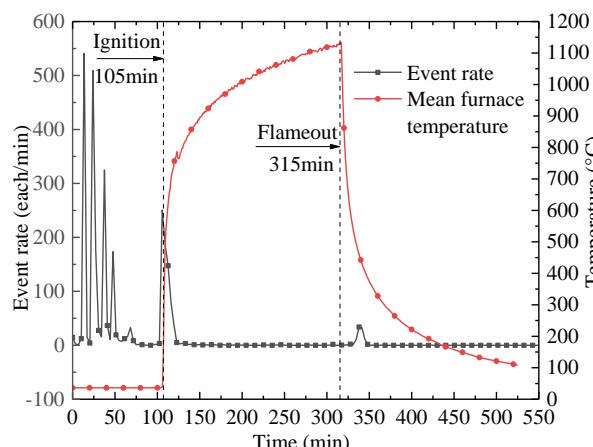

(a) 7-channel sensor

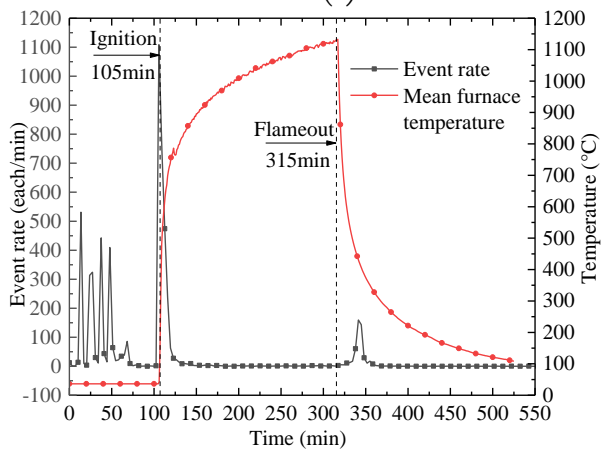

(d) 12-channel sensor

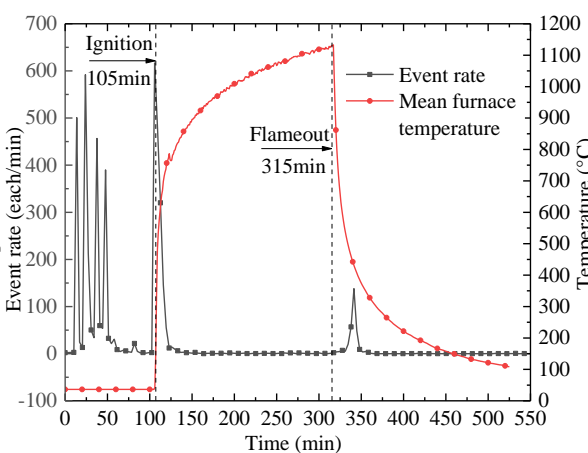

(b) 8-channel sensor

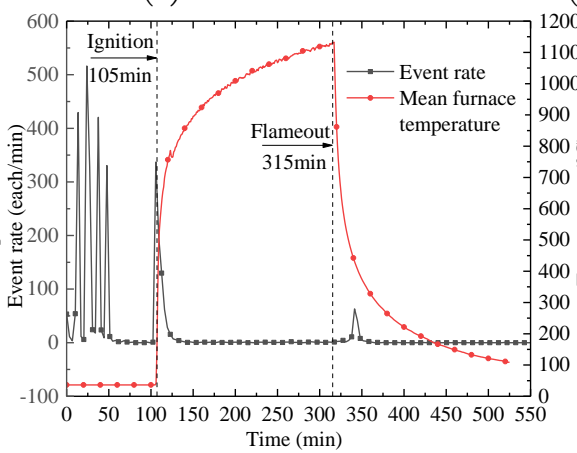

(e) 13-channel sensor

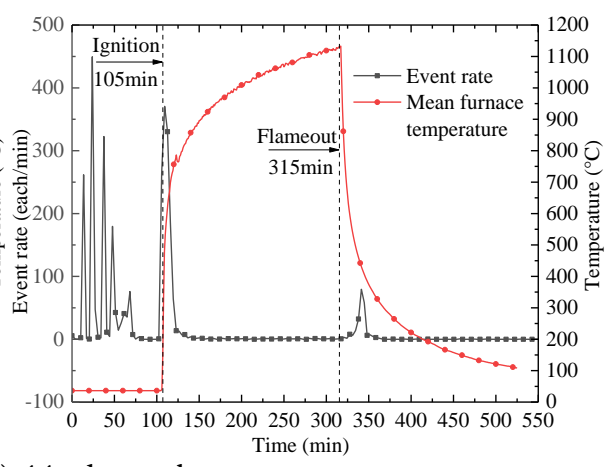

(c) 11-channel sensor

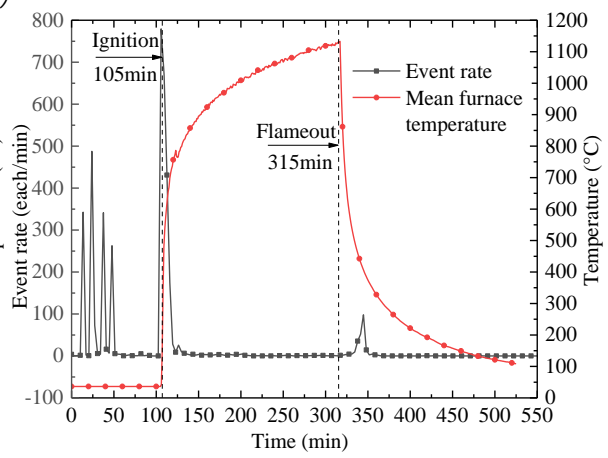

(f) 15-channel sensor

Figure 14: Variation in the event rate of $\mathrm{S} 3$ with time and furnace temperature. 


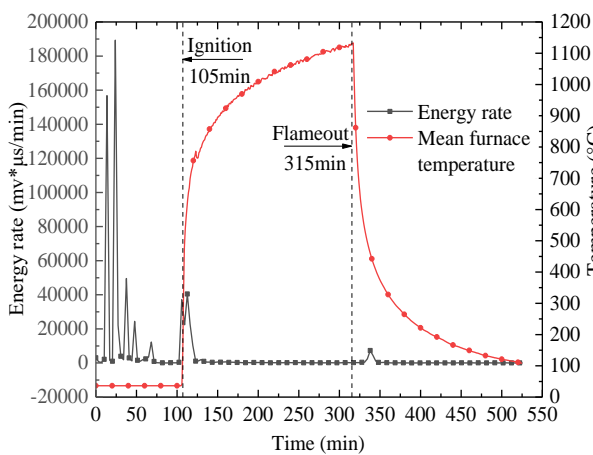

(a) 7-channel sensor

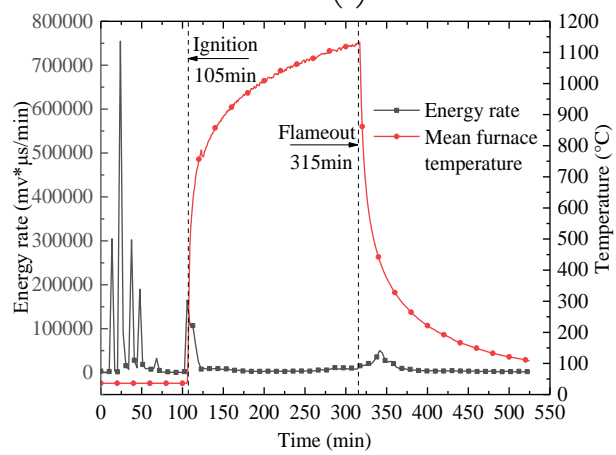

(d) 12-channel sensor

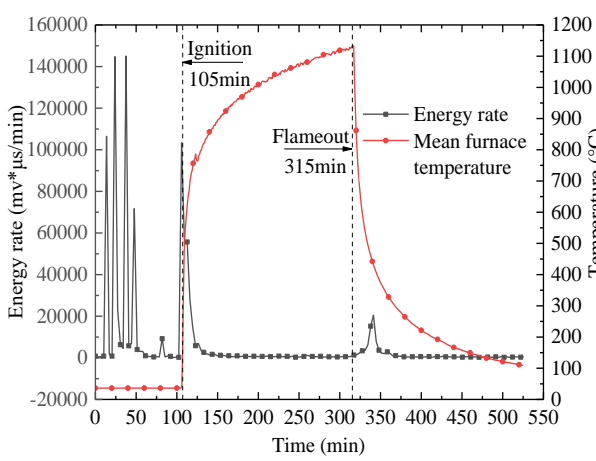

(b) 8-channel sensor

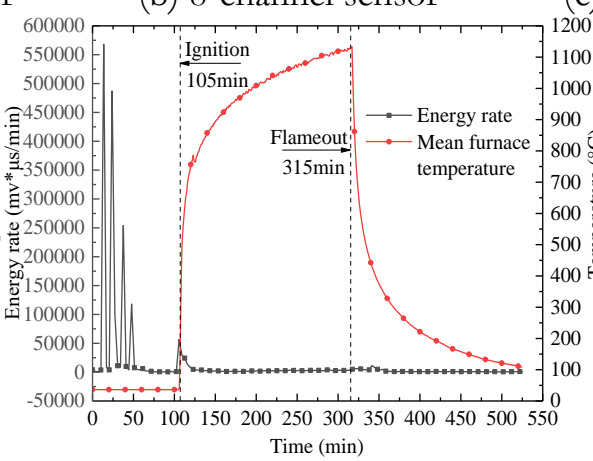

(e) 13-channel sensor

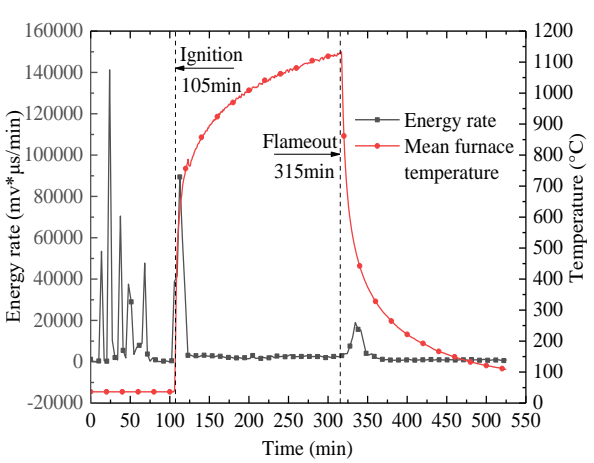

(c) 11-channel sensor

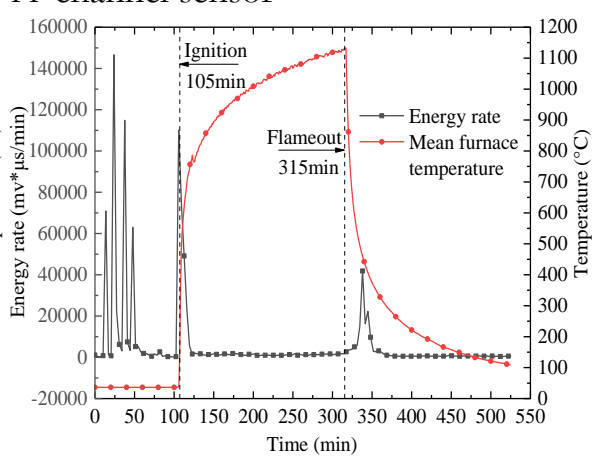

(f) 15-channel sensor

Figure 15: Variation in the energy rate of $\mathrm{S} 3$ with time and furnace temperature.

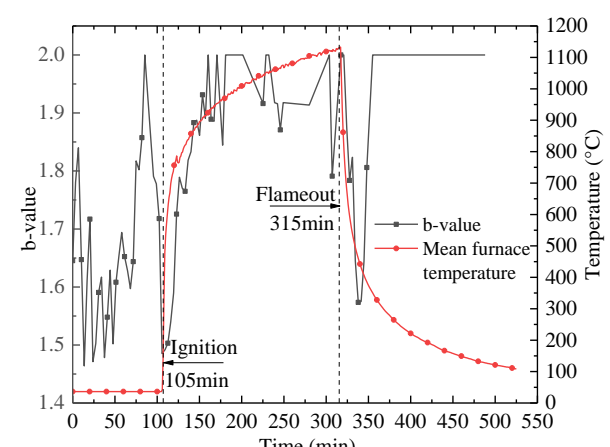

(a) 7-channel sensor

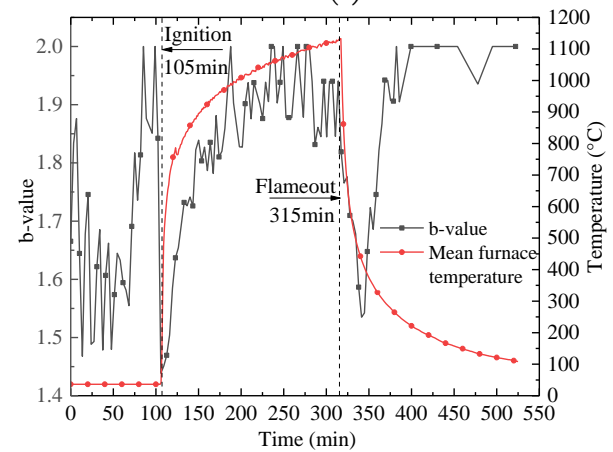

(d) 12-channel sensor

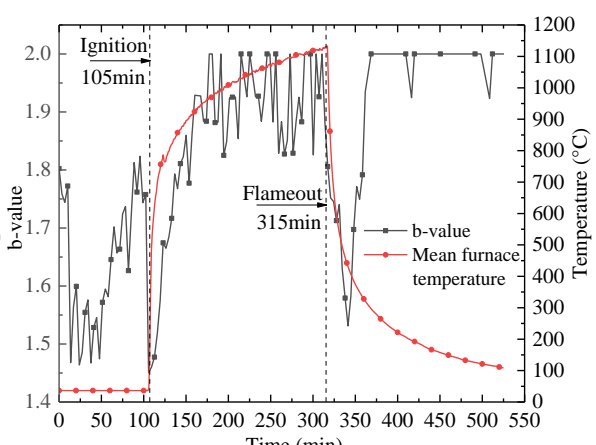

Time (min)

(b) 8-channel sensor

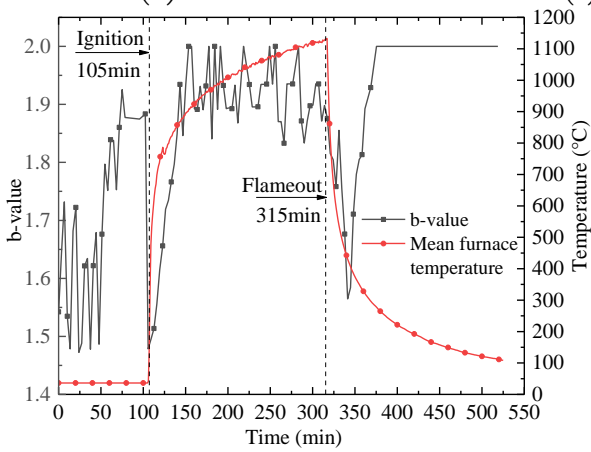

(e) 13-channel sensor

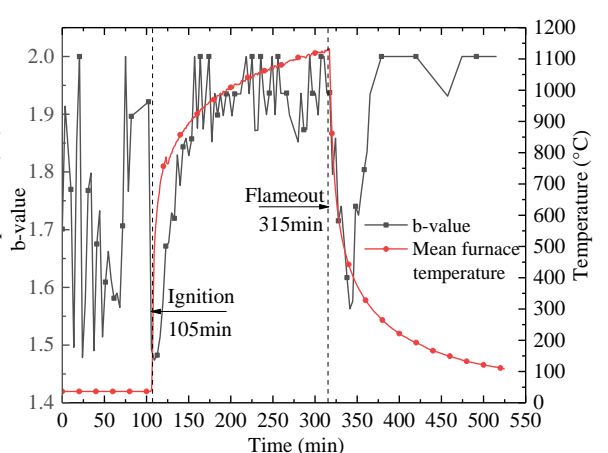

(c) 11-channel sensor

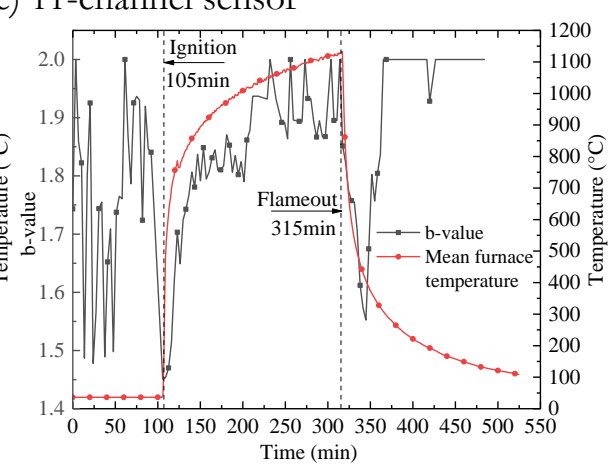

(f) 15-channel sensor

Figure 16: Variation in the b-value of $\mathrm{S} 3$ with time and furnace temperature.

Figs. 14-16 show the variations in event rate, energy rate and b-value with time and furnace temperature, respectively. Coupled with macroscopic phenomena, the change laws of the three characteristic parameters in each stage were analyzed based on the three figures: 
(1) Room temperature stage I

From zero to one min at room temperature, as the load applied by the jack gradually reached $50 \mathrm{kN}$, there was no obvious cracking or deformation on the plate surface.

As shown in Fig. 14, the event rates of measuring points were around zero events/min, and the peak event rate, 53 events/min only, was captured by $13 \#$, reflecting the rarity of cracks inside or on the plate.

As shown in Fig. 15, the energy rates of measuring points were rather low at about zero $\mathrm{mv} \cdot \mu \mathrm{s} / \mathrm{min}$. Thus, the cracks released a very small amount of energy.

As shown in Fig. 16, the first valley was observed for the b-values in all channels. The b-values at most measuring points were around 1.7-1.8, except that (1.55) at 13\#. The values were much higher than those in the subsequent loading stages at room temperature. This means the crack width in this stage was much narrower than that in other stages. That is why the cracks were not observable in this stage.

(2) Room temperature stage II

From 14 to $15 \mathrm{~min}$ (second loading stage), the load increased from 50 to $100 \mathrm{kN}$. During the loading and holding, five fine cracks appeared in the east and west of the plate, respectively. From 26 to $28 \mathrm{~min}$ (third loading stage), the load further grew from 100 to $150 \mathrm{kN}$. During the loading and holding, four fine new cracks emerged in the east, and six on the west of the plate. From 38 to $39 \mathrm{~min}$ (fourth loading stage), the load increased from 150 to $175 \mathrm{kN}$. In this process, four fine new cracks emerged in the east and the west of the plate, respectively, and the first ring crack formed on the top of the column. From 49 to 50 min (fifth loading stage), the load continued to rose from 175 to $200 \mathrm{kN}$. During this process, two new cracks emerged in the east and one on the west of the plate.

As shown in Fig. 14, with the emergence of new cracks on the edges, the penetration of cracks and the appearance of ring crack on the top of the column, the event rates of the measuring points surged up to the peak values, and then plunged in the holding period, exhibiting as serrated curves. The event rates were uniformly distributed across the different loading stages. In the second loading stage, the peak event rate $(541$ events $/ \mathrm{min})$ was recorded at $7 \#$; in the third loading stage, the peak event rate (591 events/min) was recorded at $8 \#$. In the fourth loading stage, the peak event rate (456 events/min) was recorded at $8 \#$; in the fifth loading stage, the peak event rate (409 events/min) was recorded at $12 \#$.

As shown in Fig. 15, the energy rates at measuring points rose sharply to the peak values, and nosedived in the holding period, exhibiting as serrated curves. The peak energy rates differed greatly from measuring point to measuring point. Relatively high peak values were observed at $12 \#$ and $13 \#$ through the five loading stages. In the second loading stage, the peak energy rate $(568,205 \mathrm{mv} \cdot \mu \mathrm{s} / \mathrm{min})$ was recorded at $13 \#$; in the third loading stage, the peak energy rate $(754,844$ $\mathrm{mv} \cdot \mu \mathrm{s} / \mathrm{min})$ was recorded at $12 \#$; In the fourth loading stage, the peak energy rate $(302,332 \mathrm{mv} \cdot \mu \mathrm{s} / \mathrm{min})$ was recorded at $12 \#$; in the fifth loading stage, the peak energy rate $(189,839 \mathrm{mv} \cdot \mu \mathrm{s} / \mathrm{min})$ was recorded at $12 \#$.

As shown in Fig. 16, the b-value at each measuring point hit the valley in each loading stage, and the valley values were close to each other, ranging from 1.45 to 1.50 . Therefore, the cracks developed rapidly in all loading stages.

(3) High temperature stage I

Right after the ignition at 105 min, cracks appeared quickly along the short sides on the north and south of the plate, so did diagonal cracks. Meanwhile, the cracks widened obviously at plate-column nodes. From 114 to 118 min, several popping sounds were heard consecutively, due to concrete spalling.

As shown in Fig. 14, the event rates at all measuring points reached the peaks again; all are far greater than the peaks at room temperature. The highest peak value was measured by 12\#: 1,108 events/min. This means, with the rising furnace temperature, the specimen became more active in AE under the coupling of load and temperature.

As shown in Fig. 15, the energy rates at all measuring points returned to the peaks after ignition. The highest peak energy rate $(165,293 \mathrm{mv} \cdot \mu \mathrm{s} / \mathrm{min})$ appeared at $12 \#$. The results indicate that new energy was released by new cracks and concrete spalling.

As shown in Fig. 16, the b-values at all measuring points hit the valleys quickly after ignition. The valley values were between 1.40-1.45, lower than those under room temperature. Next, the b-values gradually rebounded. It can be seen that cracks widened quickly and diagonal cracks emerged rapidly at the beginning of the fire; with the growing furnace temperature, it is increasingly difficult for new cracks to emerge and for old cracks to widen.

(4) High temperature stage II

At $121 \mathrm{~min}$, the furnace temperature was $763^{\circ} \mathrm{C}$. Four sounds of concrete spalling were heard; lots of water stains appeared in the cracks on plate surface, and seeped towards the short sides; water vapor escaped from the relatively width cracks. One concrete spalling sound was heard respectively at 131 and $133 \mathrm{~min}$. At $140 \mathrm{~min}$, the furnace temperature rose to 857 ${ }^{\circ} \mathrm{C}$. The plate height was distorted at the top of the column. At $252 \mathrm{~min}$, the furnace temperature was $1,078{ }^{\circ} \mathrm{C}$, and the water stains on the plate surface were basically evaporated. At $315 \mathrm{~min}$, the fire was turned off. 
As shown in Fig. 14, the event rates at all measuring points declined sharply to the valleys at around zero events/min. This shows that no new cracks or concrete spalling occurred in this "quiet" stage.

As shown in Fig. 15, the energy rates at all measuring points dropped deep to the valleys at around zero $\mathrm{mv} \cdot \mu \mathrm{s} / \mathrm{min}$.

As shown in Fig. 16, the b-values at all measuring points remained at a high value (2), exhibiting as serrated curves. This means, when the plate was under the same load, the crack width changed in a certain degree in the later period of heating, but the crack development was rather limited.

(5) Cooling stage

After flameout, the data collection was stopped at $550 \mathrm{~min}$.

As shown in Figs. 14 and 15, the event rates and energy rates at all measuring points surged up to the peak values between 326 and $329 \mathrm{~min}$. The $3 \mathrm{~min}$ difference is due to multiple factors, such as the attenuation of acoustic waves in the propagation path. The peak event rate $(137$ events $/ \mathrm{min})$ was measured by $8 \#$, while the peak energy rate $(50,098 \mathrm{mv} \cdot \mu \mathrm{s} / \mathrm{min})$ was captured by $12 \#$. These results indicate that, after flameout, the furnace temperature dropped sharply, and the heat was transferred from the bottom to the top of the specimen. The moisture in the plate continued to evaporate, creating temperature stress and internal stress, releasing some energy, and thus AE sources. After that, no new crack emerged, and no original crack widened. As a result, the event rates and energy rates at all measuring points dropped deeply to a low level, kicking off another "quiet" period.

As shown in Fig. 16, after flameout, the b-values of all measuring points started to decrease and reached the valleys (1.551.60) at around 326-329 min. It shows that in this stage, with the redistribution of internal forces, the internal cracks of concrete develop further. Then, the b-values gradually picked up, and the number of AE sources decreased slowly in the specimen.

\section{CONCLUSIONS}

$\mathrm{T}$ his paper mainly carried out two works: one is to record the development law of slab cracks under normal temperature and fire; the other is to use acoustic emission technology to monitor the acoustic emission signals at different positions of the specimen, and to collect the accumulated events, event rate, energy rate, $b$ value and other parameters analysis. The main conclusions are as follows:

(1) Before punch failure, the cracks mainly radiated from the center of the plate. Among them, the diagonal cracks developed quickly under fire. The cracks under high temperature could be monitored in real-time by infrared detection technology.

(2) The cumulative number of AE events can reflect the activity of the specimen. According to the test results, the cumulative number of events grew linearly in room temperature loading stages, high temperature stages and cooling stage. This means the specimen has been active in the entire process, and each stage has a "quiet" period.

(3) Throughout the test, the variation in event rate, energy rate and b-value can be split into several stages. Upon load increase or ignition, the event rate and energy rate exhibited as serrated curves, while the b-value hit the valley. The specimen suffered the most severe damage when event rate and energy rate suddenly spiked and b-value suddenly dropped. In this case, the structure could have failed. By monitoring these three characteristic parameters, it is possible to provide early warning of fire to reinforced concrete plate-column structure.

(4) The crack density and change in internal forces could be derived from the trends of event rate and energy rate. The local energy changes of the specimen could be deciphered from the curves of energy rate and b-value, making it possible to judge if a component has reached the failure state. This provides an important reference for preventing structural instability and internal damage.

However, there are several limitations of this research. Firstly, the AE testing for engineering structures under fire was only applied to reinforced concrete plate-column structure, due to the difficulty of full-scale testing. Secondly, the authors only analyzed the features and trends of some typical AE parameters due to the limited amount of test data. The analysis cannot cover all possible problems. Especially in the data collected from the acoustic emission test in this paper, there is almost no case that the number of events $\mathrm{n}$ is very small and the amplitude $\mathrm{A}$ is very large. Therefore, the calculation formula of $\mathrm{b}$ value proposed in this paper is suitable for the test in this paper. However, in the process of unstable crack growth, there are not many possible crack events, and the energy (amplitude) is large. At this time, the b value calculated by the formula in this paper is likely to be too large, resulting in misjudgment. Our attempt to apply AE techniques in fire safety of engineering structures has high universality and can be applied to various fields of civil engineering, such as health monitoring during the whole life of bridge engineering. To establish an AE-based early warning system for collapse of engineering structures under fire, more tests are needed to determine the failure thresholds of key AE parameters and realize the real-time online monitoring and damage assessment of engineering structures. 


\section{ACKNOWLEDGEMENTS}

his project was supported by the National Natural Science Foundation of China (Grant No. 51778250), The
Education and scientific research project for young and middle-aged teachers in Fujian Province (Grant No.
JAT191400).

\section{REFERENCES}

[1] Yang, X.J., Yao, C.J., Yuan, X.J., and Long, X.H. (2016). Material Damage Detection Technology Based on Acoustic Emission, Beijing: Beijing University of Aeronautics and Astronautics Press.

[2] Ji, H.G. (2004). Research and Application of Acoustic Emission Performance of Concrete Materials, Beijing: Coal Industry Press.

[3] Yuan, Z.M., Ma, Y.K., and He, Z.Y. (1985). Acoustic Emission Technology and Its Application, Beijing: Mechanical Industry Press.

[4] Chen, X.J., Cai, Y.Q., Cui, T.L. (2018). Research on acoustic emission characteristics in the whole process of pressure test of concrete, Highway and Automotive Technology, (1), pp. 134-138. DOI: 10.3969/j.issn.1671-2668.2018.01.034

[5] Kim, V.T., and Nele, D.B. (2012). Acoustic emission analysis for the quantification of autonomous crack healing in concrete, Construction and Building Materials, 28(1), pp. 333-341. DOI: 10.1016/j.conbuildmat.2011.08.079

[6] Zhang, R., Xu, G., and Jiang, Y., (2017). Acoustic emission monitoring of rusty state of reinforced concrete structures, Concrete, (1), pp. 34-43.

[7] Patil, S., Karkare, B., and Goyal, S. (2014). Acoustic emission vis-A-vis electrochemical techniques for corrosion monitoring concrete element, Construction and Building Materials, 68, pp. 326-332.

DOI: 10.1016/j.conbuildmat.2014.06.068

[8] Calabrese, L., Campanella, G., Proverbio, E. (2012). Noise removal by cluster analysis after long time AE corrosion monitoring of steel Reinforcement in concrete, Construction and Building Materials, 34, pp. 362-371.

DOI: $10.1016 /$ j.conbuildmat.2012.02.046

[9] Fan, Y.H. (2017). Research on bending damage of concrete specimens based on acoustic emission technology, Beijing Jiaotong University.

[10] Zhang, S., and Wu, C. (2017). Analysis of frequency band energy characteristics of emission signals of prestressed reinforced concrete beam damage process, Journal of Anhui Jianke University, 25(4), pp. 9-13. DOI: $10.11921 /$ j.issn.2095-8382.20170403

[11]Zitto, M.E., Piotrkowski, R., Gallego, A., Sagasta, F., and Benavent-Climent, A. (2015). Damage assessed by wavelet scale bands and b-value in dynamical tests of a reinforced concrete slab monitored with acoustic emission, Mechanical Systems and Signal Processing, 60, pp. 75-89. DOI: 10.1016/j.ymssp.2015.02.006

[12] Rao, T.E., Krishna, G.R., Kumar, M.V. (2019). Investigation of microstructure and mechanical properties of MIG welded mild steel plates, Annales de Chimie - Science des Matériaux, 43(4), pp. 257-263. DOI: 10.18280/acsm.430409.

[13] Men, J.J., Zhao, Q., Zhu, L., and Wang, X.D. (2017). Moment-tensor-based acoustic emission detection method for reinforced concrete structure, Journal of Prevention and Mitigation Engineering, 37(5), pp. 822-841.

DOI: $10.13409 /$ j.cnki.jdpme.2017.05.019

[14] Peng, G.P., Zhang, Z.D., and Lu, C. (2018). Characterization and quantitative evaluation of acoustic emission characteristic parameters of Q345R steel during tensile damage, Pilot Research, 40(1), pp. 50-54.

DOI: $10.11973 /$ wsjc201801012

[15] Long, X.J., Li, Q.F., He, C.H., Wu, Q., Chen, G., and Lu, C. (2017). Acoustic emission monitoring and evaluation of steel damage at different tensile rates, Journal of Vibration and Shock, 36(7), pp. 219-225.

[16] Song, J.B., Song, R., Xiong, Z. (2018). Acoustic radiation features and structural-acoustic sensitivity of channel beam, Traitement du Signal, 35(1), pp. 35-45. DOI: 10.3166/TS.35.35-45.

[17] Bhuiyan, M.Y., Giurgiutiu, V. (2018). The signatures of acoustic emission waveforms from fatigue crack advancing in thin metallic plates, Smart Materials and Structures, 27(1), 015019. DOI: 10.1088/1361-665X/aa9bc2.

[18] D'Angela, D., Ercolino, M., Bellini, C., Di Cocco, V., Iacoviello, F. (2020). Characterisation of the damaging micromechanisms in a pearlitic ductile cast iron and damage assessment by acoustic emission testing, Fatigue \& Fracture of Engineering Materials \& Structures. DOI: 10.1111/ffe.13214. 
[19] D'Angela, D., Ercolino, M. (2019). Acoustic Emission Entropy as a fracture-sensitive feature for real-time assessment of metal plates under fatigue loading, Procedia Structural Integrity, 18, pp. 570-576. DOI: 10.1016/j.prostr.2019.08.201.

[20] Botvina, L.R., Tyutin, M.R. (2019). New acoustic parameter characterizing loading history effects, Engineering Fracture Mechanics, 210, pp. 358-366. DOI: 10.1016/j.engfracmech.2018.06.020.

[21] Prabhu, N.M., Gopal, K.A., Murugan, S., Haneef, T.K., Mukhopadhyay, C.K., Venugopal, S., and Jayakumar, T. (2015). Determining the feasibility of identifying creep rupture of stainless steel cladding tubes on-line using acoustic emission technique, International Journal of Structural Integrity, 6(3), pp. 410-418. DOI: 10.1108/IJSI-08-2014-0038

[22] Li, B., Zhang, Y., Wen, Z.M., and Cong, X.C. (2017). Experimental Study on the acoustic emission characteristics of Q345R steel creep process, Journal of Experimental Mechanics, 32(2), pp. 232-238.

[23] Kyriazopoulos, A. (2017). Acoustic emissions and electric signal recordings, when cement mortar beams are subjected to three-point bending under various loading protocols, Frattura Ed Integrità Strutturale, 11(40), pp. 52-60.

DOI: 10.3221/IGF-ESIS.40.05.

[24] Saliba, J., Loukili, A., Regoin, J.P., Grégoire, D., Verdon, L., Pijaudier-Cabot, G. (2015). Experimental analysis of crack evolution in concrete by the acoustic emission technique, Frattura Ed Integrità Strutturale, 9(34), pp. 300-308.

DOI: $10.3221 /$ IGF-ESIS.34.32.

[25] Stavrakas, I. (2017). Acoustic emissions and pressure stimulated currents experimental techniques used to verify Kaiser effect during compression tests of Dionysos marble, Frattura Ed Integrità Strutturale, 11(40), pp. 32-40.

DOI: $10.3221 /$ IGF-ESIS.40.03.

[26] Saltas, V., Peraki, D., Vallianatos, F. (2019). The use of acoustic emissions technique in the monitoring of fracturing in concrete using soundless chemical demolition agent, Frattura Ed Integrità Strutturale, 13(50), pp. 505-516.

DOI: 10.3221 IGF-ESIS.50.42.

[27] Guo, Q.H., Xi, B.P., Tian, J.B., Li, Z.W., and Zheng, X.C. (2015). Experimental research on mechanical property of tunnel concrete lining after high temperature of fire, Chinese Journal of Underground Space and Engineering, 11(5), pp. 1316-1328.

[28] Zhu, C.J. (2012). Research on the fire resistance performance of two-way plates with full-size reinforced concrete, Harbin Institute of Technology.

[29] Zhu, C.J., Dong, Y.L., Xie, Q. (2016). Real-time monitoring of the full-scale flate-plate floor subjected to fire by acoustic emission and energy rate analysis, Transportation and Environment, (31), pp. 229-234. DOI: 10.2991/iccte-16.2016.38.

[30] Yang, Z.N. (2012). Study on the fire resistance of concrete two-way slab with different boundary constraints, Harbin Institute of Technology.

[31] Muttoni, A., Fürst, A., and Hunkeler, F. (2005). Deckeneinsturz der tiefgarage am staldenacker in gretzenbach, Solothurn, Switzerland.

[32] National Standard of the People's Republic of China. (2011). GB50010 Concrete Structure Design Specification, Beijing: China Building Industry Press.

[33] National Standard of the People's Republic of China. (2002). GB/T50081-2002(2003) Standard for test method of mechanical properties on ordinary concrete, Beijing: China Architecture \& Building Press.

[34] National Standard of the People's Republic of China. (2010). GB/T228.1-2010(2010) Metallic materials-Tensile testingPart 1: Method of test at room temperature, Beijing: China Standards Press.

[35] Wang, Y., Wang, T.Y., Yuan, G.L., An, X.L., and Dong, Y.L. (2016). Analysis of fire behavior of two-way concrete slabs based on different constitutive models, Engineering Mechanics, 33(11), pp. 208-219.

DOI: $10.6052 / j$. issn.1000-4750.2015.08.0690

[36] Dong, Y.L., Xie, H.P., and Li, Y.S. (1995). Acoustic emission characteristics and damage constitutive model of concrete under compression, Mechanics and Practice, 9(4), pp. 25-28. 